\title{
PRESSUPOSTOS EPISTÊMICO-TEÓRICOS CONVERGENTES COM A ABORDAGEM TERRITORIAL'
}

\section{EPISTEMIC-THEORETICAL BASES CONVERGING WITH THE TERRITORIAL APPROACH}

\author{
Valdir Roque Dallabrida ${ }^{2}$ \\ Edemar Rotta ${ }^{3}$ \\ Pedro Luís Büttenbender ${ }^{4}$
}

\begin{abstract}
Resumo
O presente texto, na forma de ensaio, utiliza-se da revisão da literatura para identificar pressupostos epistêmico-teóricos que sejam convergentes com a abordagem territorial. Fazer alusão à abordagem territorial é conceber o território como referência fundamental, ao se propor a análise socioeconômica, cultural e ambiental de um determinado recorte espacial. Concebe-se o território como uma construção social resultante de acúmulos, herdados de um passado longínquo ou mais recente, que se expressam contemporaneamente nas dimensões social, econômica, natural, cultural, institucional, humana e intelectual, as quais constituem o patrimônio territorial. Parte-se da compreensão de que é no campo epistemológico que se evidencia as diretrizes que orientarão o desvelamento do objeto de estudo, situando-o numa dada perspectiva paradigmática. Assim sendo, neste texto prioriza-se o foco em quatro campos epistêmicos, sendo eles, a teoria dos sistemas, a teoria da complexidade, o materialismo histórico-dialético e a perspectiva epistemológica sustentada no descentramento e decolonialidade, além da indicação de pressupostos teóricos, ambos, para serem considerados na análise territorial. O que se pretende é identificar os pressupostos epistêmico-teóricos que orientem a elaboração de procedimentos metodológicos que viabilizem o reconhecimento e análise de contextos socioeconômico-culturais e ambientais, com vistas à prospecção de alternativas inovadoras e sustentáveis de desenvolvimento territorial.
\end{abstract}

Palavras-chave: Abordagem territorial. Pressupostos epistêmico-teóricos. Patrimônio Territorial. Desenvolvimento Territorial.

\footnotetext{
Abstract

${ }^{1} \mathrm{O}$ texto faz parte do referencial teórico do Projeto de Pesquisa "Patrimônio Territorial como referência no processo de desenvolvimento de territórios e regiões", com financiamento do CNPQ-PQ.

${ }^{2}$ Doutor em Desenvolvimento Regional pela Universidade de Santa Cruz do Sul (UNISC).

Coordenador da Rede Ibero-americana de Estudos sobre Desenvolvimento Territorial e Governança. Professor visitante da Universidade Federal do Paraná, Matinhos - PR, Brasil. E-mail: valdirdallabrida@gmail.com.

${ }^{3}$ Doutor em Serviço Social pela Pontifícia Universidade Católica do Rio Grande do Sul (PUCRS). Professor da Universidade Federal da Fronteira Sul (UFFS), Campus Cerro Largo - RS, Brasil. E-mail: erotta@uffs.edu.br

${ }^{4}$ Doutor em Administração pela Universidade Federal de Mato Grosso do Sul (UFMS). Professor da Universidade Regional do Noroeste do Estado do Rio Grande do Sul (UNIJUI), Santa Rosa - RS, Brasil. E-mail: pedrolb@unijui.edu.br
} 
This text, in the form of an essay, uses the literature review in order to identify epistemic-theoretical bases convergent with the territorial approach. Referring to the territorial approach is to conceive the territory as a fundamental reference, when proposing the socioeconomic, cultural and environmental analysis of a given spatial area. The territory is conceived as a social construction resulting from accumulations, inherited from a distant or more recent past, which are simultaneously expressed in the social, economic, natural, cultural, institutional, human and intellectual dimensions, which constitute the territorial heritage. It starts from the understanding that it is in the epistemological field that the guidelines that will conduct the unveiling of the object of study are evidenced, placing it in a given paradigmatic perspective. In this text, the focus is on four epistemic fields, namely, systems theory, complexity theory, historical-dialectical materialism and the epistemological perspective sustained by decentralization and decoloniality, in addition to the indication of theoretical assumptions. Both, to be considered in the territorial analysis. Advancing from the theoretical to the operational field, taking as an example the execution of an investigation, what is intended is to identify the epistemic-theoretical bases that guide the elaboration of methodological procedures that enable the recognition and analysis of socioeconomiccultural and environmental contexts, with a view to prospecting innovative and sustainable alternatives for territorial development.

Keywords: Territorial approach. Epistemic-theoretical bases. Territorial Heritage. Territorial Development.

\section{Introdução}

A identificação dos pressupostos epistêmico-teóricos convergentes com a abordagem territorial é um desafio ainda a ser enfrentado. Esse texto assume tal desafio ${ }^{5}$. Com isso, o que se pretende é identificar os pressupostos epistêmico-teóricos que orientem procedimentos metodológicos adequados para o reconhecimento e análise de contextos socioeconômico-culturais e ambientais (recortes territoriais), tendo o patrimônio territorial como referência.

Aludir à abordagem territorial, é conceber o território como referência fundamental. $\mathrm{O}$ debate sobre território, bem como sobre abordagem territorial, nas últimas décadas, tem sido recorrente, muitas vezes com compreensões diferenciadas, a ponto de se tornar quase um modismo. Por isso, muitos autores têm se ocupado produzir reflexões que contribuam para avançar e elucidar esse debate.

De Raffestin (1993), dentre outras contribuições sobre a atualização da noção de território, depreende-se sua dimensão relacional ${ }^{6}$. $\mathrm{O}$ autor entende o território como manifestação espacial de poder, fundamentada em relações sociais determinadas por ações e estruturas concretas (energia) e simbólicas (informação). Portanto, o território resulta de relações entre atores, ressaltando sua integração relacional. A ideia de território é especialmente importante para a compreensão das dinâmicas contemporâneas porque ela permite olhar de forma relacional para domínios sobre os quais usualmente tem prevalecido leituras dicotômicas: sociedade natureza, economia, política e sociedade, rural e urbano, local e extra local (FAVARETO, 2020).

Na mesma linha de pensamento, ao se referirem ao território, Schneider e Tartaruga (2004) afirmam que ele precisa ser entendido a partir do reconhecimento das relações de poder projetadas no espaço entre os diversos atores. Como resultante, os processos de desenvolvimento territorial remetem às relações de poder, referindo-se à capacidade dos atores de tomarem decisões e transformarem/reestruturarem o espaço, impregnando novos usos sobre o território (RAMBO; FILIPPI, 2012).

\footnotetext{
5 Agradecemos aos professores Dr. Arilson Favareto (UFABC) e Dr. Sérgio Schneider (UFRGS), pelos pertinentes comentários e sugestões, os quais foram úteis para qualificar a abordagem do texto. No entanto, nós autores assumimos inteira responsabilidade pela versão final do artigo.

${ }^{6}$ Duas publicações são indicadas para aprofundar a concepção de território, além das aqui mencionadas: Fuini (2017); Saquet (2007).
} 
Sobre território, Coulert e Pecqueur (1994, p. 470) já reafirmavam que "[...] as condições históricas e culturais e as características socioeconômicas das diversas regiões jogam um papel importante, sua diversidade explica em grande parte as diferenças de trajetórias de desenvolvimento [...]". Assim, o espaço deixa de ser apenas suporte, torna-se território, como ponto de reencontro dos atores do desenvolvimento e lugar de reencontro entre formas de mercado e as formas de regulação social. Neste sentido, os territórios "[...] constituem-se em espaços particulares que permitem operar uma mediação entre o indivíduo e o exterior" (PECQUEUR, 1992, p. 84).

No entanto, os territórios, apesar de suas particularidades e especificidades, fazem parte de uma totalidade espacial ${ }^{7}$. A totalidade, precisa ser vista, não simplesmente na relação parte-todo e todo-parte, mas como num holograma em que cada parte ou cada ponto contém a totalidade e viceversa, não admitindo um pensamento mutilante pautado pelo reducionismo que não se mostra capaz de ordenar as informações e os saberes de um mundo dinâmico. Resumindo, a abordagem territorial considera o território como parte da totalidade espacial, em que se expressam a diversidade, a relacionalidade e interação entre atores; (ii) a interdependência entre as dimensões tanto materiais quanto imateriais e lócus de manifestação de sistemas produtivos localizados, de mediação e interdependência entre sociedade e natureza (LIMA, 2010).

Em relação à abordagem territorial, desde o início do debate sobre o tema até sua aplicação nas políticas públicas no Brasil, na primeira década do Século XXI, ela propunha-se contribuir na superação do enfoque setorial das atividades econômicas e da dicotomia espacial entre o rural versus urbano, sendo substituída pela diversidade de ações, estratégias e trajetórias que os atores adotam visando a sua reprodução social e econômica (SCHNEIDER, 2009). Apesar de alguns avanços, avaliações realizadas mostram diferentes percalços e lacunas ${ }^{8}$.

Para Schneider e Tartaruga (2004), entre as razões da reafirmação da abordagem territorial, resulta, primeiro, da profusão da literatura que interpreta o contexto das transformações societárias do final do Século XX e início do Século XXI, como resultado da crise do fordismo e do processo de reestruturação do capitalismo, caminhando para o que Piore e Sabel (1984) chamaram de “acumulação flexível”. Isso teria permitido a descentralização de plantas industriais, juntamente com a flexibilização do processo de produção, a exemplo de estratégias de terceirização, formandose nas áreas menos dinâmicas, aglomerados produtivos e sistemas produtivos locais ou regionais, dentre outras denominações. Como resultado, ampliou-se o entendimento de que os processos de crescimento industrial que apresentavam melhores indicadores seriam aqueles que estavam assentados em dinâmicas territoriais específicas.

“A segunda razão que favoreceu o interesse pela abordagem territorial está relacionada aos aspectos políticos e institucionais que derivam, basicamente, da crise do Estado e da perda crescente de seu poder de regulação [...]" (SCHNEIDER; TARTARUGA, 2004, p. 108). As novas tecnologias de base microeletrônica e telemática (telecomunicações e informática) contribuíram decisivamente para a consolidação do processo de globalização ou mundialização que caracteriza a sociedade e a economia contemporânea. Como resultado, o Estado passou a sofrer sucessivas alterações nas suas funções e incumbências, deixando de ser indutor do desenvolvimento, para ser regulador, alterando seu caráter centralizador, permitindo a participação das diversas instâncias e organizações da sociedade civil (SCHNEIDER; TARTARUGA, 2004).

A emergência da abordagem territorial, em terceiro lugar, tem relação com a crise do paradigma agrário e das abordagens setoriais e produtivistas na agricultura. $O$ enfoque setorial sobre desenvolvimento rural, predominante desde o pós-guerra, apostava na modernização agrícola como motor de transformação no âmbito rural (BERDEGUÉ; FAVARETO, 2020). Neste sentido, Veiga (2002) resume as três principais tendências que levaram à renovação desse discurso: (i) a diversificação da economia rural e a queda do peso da agricultura no produto interno bruto; (ii) a insuficiência das estratégias baseadas na especialização setorial e novas apostas baseadas em articulações e vínculos intersetoriais; (iii) a crítica ao planejamento centralizado de políticas públicas, tanto na perspectiva econômica, quanto desde a lógica da construção de sociedades mais democráticas ${ }^{9}$.

\footnotetext{
${ }^{7}$ Dallabrida (2020a) propõe "significar territórios”, como estratégia de diferenciação e reafirmação da identidade territorial, considerando suas especificidades.

${ }^{8}$ Para uma avaliação contemporânea desse debate sugere-se Berdegué e Favareto (2020).

${ }^{9}$ Algumas publicações são referenciais na introdução e aprofundamento do debate sobre desenvolvimento territorial rural no Brasil e América Latina. Por exemplo: Abramovay, 1999; Wanderley, 2000; Veiga, 2002; Schneider, 2004; Favareto (2007; 2010).
} 
É fundamental registrar que a difusão da abordagem territorial no Brasil e nos demais países latino-americanos teve uma contribuição importante do Programa Ligações entre Ações do Desenvolvimento da Economia Rural (LEADER), da União Europeia, influenciando a orientação de programas ou políticas públicas com foco na abordagem territorial.

Abramovay (2010) relembra que a abordagem territorial do processo de desenvolvimento ganhou força a partir do início da década de 1980, com base na literatura neomarshalliana, a qual soube identificar nos laços diretos entre os atores sociais uma das razões para a formação de sistemas produtivos localizados em regiões italianas, estudos que foram da maior importância para o entendimento de experiências brasileiras de industrialização difusa ${ }^{10}$.

Portanto, indicativamente, os princípios da totalidade, diversidade, especificidade, pluralismo, relacionalidade, integração, interdependência sistêmica, autonomia de ação e mediação entre as partes constituintes têm uma estreita relação com a base epistêmica que sustenta a abordagem territorial. Esses princípios são propostos e discutidos por correntes epistemológicas que se desenvolveram nas últimas décadas a partir do questionamento do paradigma cartesiano, além da tentativa de superação de uma visão centralmente europeísta, tais como, a Nova Teoria dos Sistemas, a Teoria Da Complexidade, o Materialismo Histórico-Dialético e a perspectiva epistemológica sustentada Decolonialidade e no Descentramento ${ }^{11}$, e sua relação com o enfoque territorial.

Antes adentrar no âmago do conteúdo do presente artigo, é necessário serem feitos dois registros. O primeiro, de Favareto (2020) que, ao reconhecer o território como categoria síntese útil à análise dos fenômenos contemporâneos, faz o alerta de que falar em territórios implica olhar para quatro ordens de interdependências: (i) interdependências entre o local e extra local, pois, embora a ideia de território coloque ênfase nos aspectos endógenos, seria um erro analisá-lo de maneira autárquica, tornando-se necessário considerar uma determinação mútua entre o local e o extra local, admitindo, inclusive, que o tecido social local pode reorientar, rechaçar, ou simplesmente absorver estas forças externas: (ii) interdependências entre sociedade e natureza ${ }^{12}$, pois os territórios são unidades formadas por sistemas sociais e pelos sistemas naturais sem os quais não há atividade econômica e tampouco há vida humana; (iii) interdependências entre dimensões da realidade (sociedade e natureza, dimensões econômica e social, política e cultural). No entanto, disso decorre a necessidade de desvelar qual dessas dimensões preside a conformação da dinâmica dos territórios, já que neles ocorre a disputa entre os diferentes atores territoriais pelo controle de seus recursos. Remete-se, então, à questão do poder, exigindo a necessidade reconhecer o modo de dominação, ou seja, reconhecer de que forma certos grupos sociais mobilizam os recursos materiais e imateriais do território para justificar e sustentar a dominação.

Uma segunda questão, levantada por Schneider e Tartaruga (2004), versa sobre o uso instrumental ou analítico do território. Segundo tais autores, as abordagens territoriais sobre desenvolvimento, em geral, se apresentam como a-teóricas, por se prenderem quase que exclusivamente no foco instrumental e prático. Já o foco analítico requer que se estabeleçam referenciais epistêmico-teóricos. É por isso que, para tentar superar esta lacuna, aqui, ao se propor tomar o território com seu patrimônio como referência na análise e proposição de estratégias inovadoras e sustentáveis de desenvolvimento para municípios, regiões ou territórios, propõe-se fazê-lo, sustentado em um referencial epistêmico-teórico que seja convergente com a abordagem territorial, conforme já referido.

Portanto, este texto, propõe-se refletir sobre estas e outras questões, quiçá, podendo contribuir na superação do desafio teórico da identificação dos pressupostos epistêmico-teóricos convergentes com a abordagem territorial. A motivação desta tentativa hercúlea provém de um outro desafio. A referência é um projeto de pesquisa proposto por um grupo de intelectuais brasileiros, latino-americanos e europeus, cujo objetivo central é elaborar estudos, propor e validar referencial metodológico com o fim de contribuir na elaboração de diagnósticos territoriais que permitam a prospecção de alternativas inovadoras e sustentáveis de desenvolvimento, tendo o patrimônio

\footnotetext{
${ }^{10}$ Sobre as experiências de industrialização difusa no Brasil, sugere-se uma publicação: Raud (1999).

11 A perspectiva da decolonialidade está sustentada em vários autores, alguns deles aqui referenciados. Já, sobre descentramento, trata-se de uma abordagem feita há mais tempo por Milton Santos. Apesar dos dois enfoques utilizarem linguagens diferentes, considera-se que eles convergem na sua perspectiva teórico-prática.

$12 \mathrm{Na}$ concepção de desenvolvimento territorial aqui assumida, a sustentabilidade ambiental é considerada condição indispensável.
} 
territorial como referência ${ }^{13}$. Portanto, este texto servirá como suporte teórico-epistemológico orientativo na proposição do referencial metodológico.

O patrimônio territorial é aqui concebido como o conjunto de ativos e recursos, materiais e imateriais, que se acumularam ao longo da história num determinado território, resultante de processos históricos de construção e reconstrução socioeconômica e cultural, na relação com o entorno ambiental. Inclui tanto os elementos herdados do passado longínquo, quanto os que se sobrepõem ao território constantemente (DALLABRIDA, 2020d, p. 12).

O presente texto, metodologicamente, caracteriza-se como um ensaio teórico, tendo como referenciais uma parte da literatura contemporânea e algumas publicações clássicas. Assim, além dessa introdução, o texto está estruturado em mais duas partes (pressupostos epistemológicos e pressupostos teóricos), além das considerações finais.

\section{Pressupostos epistemológicos}

\section{Epistemologia: etimologia e seus principais fins}

Uma primeira interrogação, é procedente: o que vem a ser a epistemologia? Lima (2010, p. 117) assim sintetiza: "Do grego episteme (conhecimento, ciência) + logos (discurso, teoria, tratado, estudo de) temos a etimologia da palavra epistemologia, consistindo na teoria ou tratado sobre a ciência ou teoria do conhecimento". Segundo o autor, também pode-se referir à epistemologia como o ramo da Filosofia que estuda a investigação científica e seu produto, o conhecimento científico.

Para Japiassu (1981, p. 58), o papel da epistemologia é “[...] estudar a gênese e a estrutura dos conhecimentos científicos com um viés interdisciplinar, pois observa a ciência sob o prisma de diversas disciplinas". Para o autor, a epistemologia trata dos estudos e reflexões acerca dos métodos científicos, realizando um "[...] estudo crítico dos princípios, das hipóteses e dos resultados das diversas ciências" (p. 24). Portanto, é no campo epistemológico que ficam claras as diretrizes que orientarão o desvelamento do objeto de estudo, situando-o numa dada perspectiva paradigmática (LIMA, 2010).

Bachelard (1990) propôs a construção de uma epistemologia histórico-crítica, que estude a ciência em seu processo de crescimento e desenvolvimento, isto é, sua história e como esta deveria ser realizada. $O$ ponto de vista do autor converge para a crença de que o progresso é o elemento mobilizador, dinâmico da cultura científica, e é esse elemento que "a história das ciências" deve descrever, de forma a julgá-lo e valorizá-lo, eliminando toda e qualquer margem de retorno às concepções equivocadas. Assim há que se "[...] formular uma história recorrente, uma história que se esclarece pela finalidade do presente, uma história que parte das certezas do presente e descobre, no passado, as formações progressivas da verdade" (p. 205-207). Nesse sentido, a proposição da epistemologia bachelardiana visa à produção dos conhecimentos científicos, abrangendo todos os seus aspectos: lógico, ideológico, ontológico e histórico (LIMA, 2010).

Quando se propõe ter como referência o patrimônio territorial, em síntese, está se propondo estudos focados na abordagem territorial do desenvolvimento. A referência teórica se sustenta nos quatro campos epistêmicos adiante mencionados.

\section{Da Teoria Geral dos Sistemas à Nova Teoria dos Sistemas}

Originalmente, um sistema é um conjunto de elementos em interação. No entanto, Bauer (2009), passa uma compreensão mais detalhada: (i) um sistema é um todo organizado e complexo; (ii) sistema é um conjunto de elementos interdependentes, cujo resultado final é superior ao somatório dos resultados que esses elementos teriam caso operassem de forma isolada; e (iii) sistema é qualquer conjunto de partes reunidas, desde que caracterizado pelas relações entre partes e pelo comportamento do todo (BAUER, 2009).

Já Lucas Jr. (1987, p. 18), ao se referir a um sistema, define-o como um conjunto de componentes e variáveis organizadas, interdependentes e integradas. Um sistema tem objetivos e metas e, às vezes, estas metas são difíceis de identificar. Segundo o autor, o ambiente ou entorno é exterior ao sistema, abarcando tudo o que está fora do mesmo. $\mathrm{O}$ ambiente também determina, em boa parte, os propósitos do sistema, por isso, o sistema e seu entorno estão inter-relacionados e são

\footnotetext{
${ }^{13} \mathrm{O}$ título do projeto de pesquisa é $O$ patrimônio territorial como referência no processo de desenvolvimento de territórios ou regióes: pressupostos epistêmico-teóricos e proposta de instrumental metodológico, proposto no segundo semestre de 2020 , portanto, ainda na sua fase inicial.
} 
interdependentes. E finaliza: "[...] os recursos são os meios de que dispõe o sistema para executar as atividades necessárias ao alcance dos objetivos. Ao contrário do ambiente, os recursos estão dentro do sistema e estão sob seu controle".

Pode-se depreender da argumentação do referido autor que, ao considerarmos o território como um sistema, não se pode esquecer que nem tudo é factível de ser controlado a partir do território, com exceção dos seus ativos ou recursos, representados neste texto pelo patrimônio territorial. Assume-se a acepção de recurso e ativos proposta por Benko e Pecqueur (2001, p. 41). "Entende-se por ativo, os fatores em 'atividade', enquanto, por recursos, os fatores a revelar, a explorar, ou ainda a organizar. Os recursos, diferentemente dos ativos, constituem assim uma reserva, um potencial latente”.

A teoria geral dos sistemas (TGS) surge nos estudos sociais e organizacionais com o intuito de sanar o reducionismo e o mecanicismo que permeava o funcionalismo clássico (SANTOS; PELOSI; OLIVEIRA, 2012). Assim, a TGS apresenta uma análise mais complexa da realidade social e aponta para uma reorientação da visão do observador para a diversidade, as inter-relações e os mecanismos de adaptação que ocorrem no sistema e entre ele e o ambiente. Além disso, a TGS resolveu aparentemente o problema do reducionismo ao incorporar o holismo como novo princípio (MORIN, 2005a).

Gusdorf (1953), um filósofo francês, foi um dos primeiros estudiosos a sistematizar uma proposta de trabalho interdisciplinar. A obra deste autor foi difundida no Brasil por Japiassu (1976; 1981), que considerava a interdisciplinaridade como um processo em que há interatividade mútua e todas as disciplinas que participam do processo devem influenciar e ser influenciadas umas pelas outras. Há uma aproximação teórica entre a discussão sobre interdisciplinaridade e pensamento ou enfoque sistêmico. As discussões basilares que permitiram a sistematização do pensamento sistêmico foram descritas ao longo da história por Capra (1996). Segundo o autor, o primeiro fundamento do pensamento sistêmico é a mudança das partes para o todo. Assim, os sistemas vivos são totalidades constituídas, cujas propriedades não podem ser reduzidas às de partes menores, com o que suas propriedades fundamentais, são propriedades do todo, que nenhuma das partes possui. Embora o pensamento mecanicista tenha sido resistente foi a visão holística construída ao longo dos séculos, que se afirmou e deve permanecer, devido aos seus fundamentos serem apropriados para todos os tipos de sistemas.

As principais crítica à TGS referem-se à tentativa de explicar os fatos sociais por meio de conceitos advindos das ciências naturais e sua tendência em desconsiderar os aspectos socioantropológicos e culturais específicos dos atores e das formações sociais específicas. No primeiro caso, se o funcionalismo parte da matemática e da física para formular suas teorias acerca do universo, o sistemismo parte das ciências biológicas e por isso não supera a tendência que condiciona as ciências sociais à racionalidade das ciências da natureza, em que não se leva em conta o papel da cultura e da intencionalidade emancipada sobre a realidade (SANTOS; PELOSI; OLIVEIRA, 2012). No segundo, denota-se o fato das teorias sistêmicas privilegiarem as lógicas estruturais dominantes, encontrando dificuldades para lidar com as dimensões contraditórias, processuais, dinâmicas e específicas que provém de lógicas diversas, para além das estruturais dominantes (LONG, 2007; OLIVIER DE SARDAN, 2007; LAGO e ROTTA, 2018).

Bechmann e Ster (2001) se referem à contribuição de Niklas Luhmann, destacando que esse autor procura superar a tendência de empregar a racionalidade das ciências da natureza para a análise das ciências sociais ao propor um conceito de sistema formado de maneira estritamente relacional, sendo que sistema, para esse autor, quer dizer uma série de eventos ou operações, interrelacionados. "No caso de seres vivos, por exemplo, esses são processos fisiológicos; no caso de sistemas psíquicos, os processos são ideias; e em termos de relações sociais, são comunicações" (BECHMANN; STER, 2001, p. 190). Os sistemas se formam e afirmam sua identidade ao se distinguirem entre si e do ambiente no qual os eventos e operações ocorrem. Porém, essa fronteira constitutiva não é espacial, mas sim operacional, pois, ao mesmo tempo em que garante a identidade/diferenciação, possibilita a relação.

Luhmann (1997, p. 1144) afirma que "O paradoxo é a ortodoxia do nosso tempo". Visto dessa forma, segundo o autor, a comunicação e, portanto, a sociedade, e em particular a sociedade moderna diferenciada funcionalmente, são construídas, em essência, sobre paradoxos. Para o autor, os paradoxos nos nossos sistemas funcionais não conduzem a um bloqueio de suas operações. Esses paradoxos são a condição para o desenvolvimento criativo. Para Luhmann, os paradoxos, nos nossos 
sistemas funcionais, não conduzem a um bloqueio de suas operações. Esses paradoxos são a condição para o desenvolvimento criativo (MOELLER, 2015).

Schad et al. (2015) definiram paradoxos como contradições persistentes entre elementos interdependentes. Segundo essa compreensão, um paradoxo contém três ingredientes: tensão, interdependência e persistência. Em primeiro lugar, um paradoxo envolve a tensão, uma contradição entre dois elementos. Em segundo, diferentemente do que sucede num dilema, a contradição entre os dois elementos é interdependente. Isto é, uma decisão sobre uma matéria tem implicações para uma matéria situada num polo oposto. Por outras palavras, a tensão comporta uma dimensão de interdependência. Os dois polos formam uma dualidade. Finalmente, a contradição persiste no tempo. Não se elimina, não é temporária. Os paradoxos podem ser generativos ou degenerativos. Se a relação entre a tensão for usada como fonte de sinergia, o paradoxo pode tornar-se uma janela aberta sobre novas possibilidades. Mas os paradoxos podem gerar confusão e paralisia. Tornam-se, então, uma fonte de escolhas debilitantes.

As contradições fazem parte do contexto contemporâneo, sendo crescente a aceitação de que os paradoxos não são anomalias a evitar ou a eliminar, mas antes uma decorrência do próprio processo organizacional. As contradições não são interrupções à ordem organizacional, mas parte dessa mesma ordem (CUNHA; REGO; SOUSA, 2016).

Sobre a questão dos paradoxos e a resultante complexidade paradoxal, Moeller (2015) faz uma síntese.

Como construções sociais contingentes, meios de comunicação, tais como o poder (político), a verdade (acadêmico) e as leis (jurídico), são constituídos paradoxalmente, e isso lhes concede sua flexibilidade e produtividade, especialmente em relação à sua evolução ou a seus desenvolvimentos no tempo. $\mathrm{O}$ poder é considerado autoridade, mas sua reversão contínua constitui a autopoiesis da política. A verdade é considerada durável, mas sua modificação contínua constitui a autopoiesis do sistema acadêmico. As leis são consideradas obrigatórias, mas sua revisão contínua constitui a autopoiesis do sistema jurídico. Os paradoxos inerentes aos meios de comunicação podem ser desenvolvidos, e esse próprio desenvolvimento constitui a evolução social (MOELLER, 2015, p. 174).

A teoria de Luhmann é fundamentalmente paradoxal, não apenas porque é parte do que ela descreve e, assim, muda seu objeto enquanto o descreve, mas também porque ela surge como uma operação social ou comunicativa fundada sobre modos paradoxais de observação (MOELLER, 2015, p. 178).

Portanto, sintetizando, segundo a perspectiva teórica luhmanniana, a autoconstrução da sociedade como um sistema complexo de funções de comunicação baseia-se no desenvolvimento de paradoxos que, por sua vez, se fundamenta no paradoxo da observação. Assim, a construção social não opera pela eliminação de paradoxos, mas por meio deles (MOELLER, 2015).

É possível relacionar a acepção de território e, sua forma de expressão, o patrimônio territorial, com a ideia de sistema. O território poderia ser considerado, então, como um todo organizado, composto por componentes interdependentes e integrados (a dimensões social, econômica, cultural, natural, institucional, humana e intelectual). Apesar da interdependência e integração de seus componentes, é parte de um todo maior, o ambiente ou entorno externo, assim sendo, podendo interferir no contexto territorial. No entanto, os recursos do território (patrimônio territorial), “[...] são os meios de que dispõe o sistema para executar as atividades necessárias ao alcance dos objetivos. Ao contrário do ambiente, os recursos estão dentro do sistema e estão sob seu controle" (LUCAS JR., 1987, p. 18).

Percebem-se, portanto, tanto os limites, quanto as possibilidades de ação coletiva na dinâmica territorial. Quando se faz referência ao patrimônio territorial, ao se propor prospectivas territoriais, então, está se falando das possibilidades, como alternativas de superação das limitações. As ideias de conexão, diversidade, interação e paradoxos, da mesma forma, dialogam com a possibilidade de pensar o futuro dos territórios ou regióes, considerando a perspectiva territorial.

\section{A Teoria da Complexidade}

Para Morin (1996), o maior propósito da complexidade é "[...] prestar contas das articulações despedaçadas pelos cortes entre disciplinas, entre categorias e entre tipos de conhecimento", tendendo para o conhecimento multidimensional, isto é, estudar e respeitar as diversas dimensões de um fenômeno, uma vez que o homem é um ser biológico-sociocultural e que os fenômenos sociais surgem e são, ao mesmo tempo, do contexto econômico, psicológico, cultural etc. Consequentemente, 
o pensamento complexo em sua multidimensionalidade, “[...] comporta em seu interior um princípio de incompletude e incerteza" (p. 177).

A partir de Morin (1996), pode-se afirmar que o pensamento complexo é uma elaboração mais refinada da teoria dos sistemas, que iniciou pela quebra do paradigma mecanicista, o embate entre o reducionismo e o expansionismo, ou holismo, em que se busca ver o mundo em termos de uma ordem ou um fundo em que todas as coisas encontram seu lugar ou sentido. A partir do modelo da teoria dos sistemas surge o paradigma da Teoria do Pensamento Complexo. Essas duas orientações epistêmicas não só estão delimitadas por um compêndio histórico, senão, antes de tudo por um hermenêutico: a compreensão da realidade a partir de suas diversas dimensões interrelacionadas.

Morin (2007, p. 13) refere-se à complexidade, como um tecido de constituintes heterogêneas inseparavelmente associadas, recolocando “[...] o paradoxo do uno e do múltiplo". Complexidade é efetivamente o tecido de acontecimentos, ações, interações, retroações, determinações e acasos que constitui o universo fenomênico... Assim, a própria reprodução da espécie é ela mesma influenciada pela sociedade que por meio de sua cultura estabelece as regras da vida em comum (SANTOS; PELOSI; OLIVEIRA, 2012, p. 64).

Nestes termos, seguindo a perspectiva epistêmica de Edgar Morin, segundo reafirma Lima (2010), o objetivo do conhecimento não é fornecer uma resposta absoluta e completa em si como última palavra, mas é abrir o diálogo e não o enclausurar, pois não existe corte epistemológico radical, assim como não há uma ciência pura, não há uma verdade final acerca de qualquer objeto e não há uma lógica pura. Thrift (1999) considera a teoria da complexidade como um amálgama científico, um híbrido retórico, afirmando, ainda, que a razão principal para sua popularidade reside no seu caráter anti-reducionista.

Morin (2005a) propõe o reconhecimento da circularidade nas explicações simultâneas do todo pelas partes e das partes pelo todo, ou seja, ambas essas explicações são complementares, sem que nenhuma possa anular as características antagônicas e concorrentes da outra. Três circularidades são propostas pelo autor, que constrói uma visão complexa da realidade: (i) a circularidade todo $\mathrm{X}$ partes, ou seja, "[...] a visão simplificada diria: a parte está no todo. A visão complexa diz: não só a parte está no todo; o todo está no interior da parte que está no interior do todo!” (MORIN, 2007, p. 88); isso é verdade também para a sociedade que desde nossa infância se imprime como todo em nossa mente, por meio da linguagem, da cultura, das crenças e saberes, resultando que o indivíduo está na sociedade, que está no indivíduo (SANTOS; PELOSI; OLIVEIRA, 2012); (ii) circularidade unidade $\mathrm{x}$ diversidade, implica que o todo existe enquanto uma única unidade global, mas as partes têm dupla identidade, preservando suas identidades próprias, não redutíveis ao todo e também constituindo uma identidade comum; assim, ao mesmo tempo em que a diversidade constrói a unidade, a unidade constrói a diversidade (MORIN, 2007; SANTOS; PELOSI; OLIVEIRA, 2012); (iii) a circularidade ordem x desordem, que exprime a essência do sentido de complexidade, dá-se entre as instâncias da ordem e da desordem. "O que digo a respeito da ordem e da desordem pode ser concebido em termos dialógicos” (MORIN, 2007, p. 74). Entre indivíduos e sociedade, que se complementam, também existem antagonismos, que vêm da oposição entre egocentrismo e sociocentrismo (BAUER, 2009).

Santos, Pelosi e Oliveira (2012) ressaltam que Morin traz à tona a emergência do sujeito e, consequentemente, da autonomia. Mundo e sujeito são colocados em situação de reciprocidade e inseparabilidade. Surge então o conceito de autonomia dependente: não há sociedade sem indivíduos e não há indivíduos propriamente humanos dotados de espírito, linguagem e cultura sem sociedade. Ao mesmo tempo em que o indivíduo recebe influências do seu meio cultural, também é dotado de autonomia inata, que inibe o total determinismo cultural e social.

Para Morin (2005b) a sociedade que mais favorece as autonomias individuais é a sociedade complexa. "A alta complexidade está ligada ao desenvolvimento das comunicações, das trocas econômicas e de ideias, ao jogo dos antagonismos entre interesses, paixões e opiniões" (MORIN, 2005b, p. 274). Quanto maior os pluralismos no campo econômico, político e cultural, maior são as possibilidades de liberdade e escolha individual e menos nossa vida é programada em relação aos genes, à sociedade e à cultura. "A complexidade social limita a exploração e a subjugação do indivíduo ao aparelho do Estado e das normas sociais, permitindo autonomia física, mental e espiritual" (SANTOS; PELOSI; OLIVEIRA, 2012, p. 65).

Assim como a teoria dos sistemas, a teoria da complexidade não é isenta de críticas. Andrade (2007, p. 167) refere que ela é “[...] marcada por um forte apelo metafísico, quando essa pretende 
estabelecer um conhecimento a priori e inédito apoiado supostamente num dado empírico ou mais precisamente na complexidade do real". Sousa Santos (2007) também traz algumas questões à tona ao afirmar que a teoria se centra na defesa do princípio da igualdade, mas foi incapaz de reconhecer as diferenças, o que se opõe à própria realidade. Nesse sentido, o autor vê na teoria da complexidade uma outra maneira de entender o mundo em termos políticos e epistemológicos, não numa aderência ao relativismo, mas antes numa convivência entre movimentos que, mesmo distintos, comungam em pontos fundamentais, em especial, nos ideais emancipatórios e na defesa de propostas contrahegemônicas, o que poderá sinalizar avanços importantes.

Dentre outras possibilidades de estabelecer uma relação entre a concepção de complexidade e o contexto territorial, é associar com alguns princípios: (i) o anti-reducionismo; (ii) o pluralismo; (iii) a multidimensionalidade; (iv) a incompletude e incerteza. Em síntese, segundo a concepção moriniana, a compreensão da realidade a partir de suas diversas dimensões inter-relacionadas, trata-se da tentativa de superar as "articulações despedaçadas" propostas pelas abordagens disciplinares ou setoriais. Ou seja, trata-se de avançar na compreensão da realidade a partir de suas diversas dimensões inter-relacionadas.

\section{0 materialismo histórico-dialético}

A dialética que aparece no pensamento de Marx surge como uma tentativa de superação da dicotomia, como a separação entre o sujeito e o objeto. No entanto, a dialética surgiu na história do pensamento humano muito antes de Marx, já encontrando aproximações entre filósofos da Grécia antiga.

É com Hegel, filósofo alemão que viveu de 1770 a 1831, que a dialética retoma seu lugar como preocupação filosófica e importante objeto de estudo da Filosofia. Hegel tratou da elaboração da dialética como método, preconizando o princípio da contradição, da totalidade e da historicidade (NOVELLI; PIRES, 1996). Porém, é com Karl Marx, filósofo e militante político alemão que viveu entre 1818 a 1883, que a dialética é apresentada como método materialista histórico, que fundamenta o pensamento marxista, podendo ser entendida como um caminho epistemológico que fundamente o conhecimento para a interpretação da realidade histórica e social (PIRES, 1997).

Para o pensamento marxista, importa descobrir as leis dos fenômenos de cuja investigação se ocupa, captar, detalhadamente, as articulações dos problemas, analisar as evoluções e rastrear as conexões sobre os fenômenos que os envolvem (PIRES, 1997). Para a autora, isso só foi possível a partir da reinterpretação do pensamento dialético de Hegel.

A lógica formal não consegue explicar as contradições e amarra o pensamento impedindolhe o movimento necessário para a compreensão das coisas. Se o mundo é dialético (se movimenta e é contraditório) é preciso um Método, uma teoria de interpretação, que consiga servir de instrumento para a sua compreensão, e este instrumento lógico pode ser o método dialético tal qual pensou Marx...

É com esta preocupação que Marx deu o caráter material (os homens se organizam na sociedade para a produção e a reprodução da vida) e o caráter histórico (como eles vêm se organizando através de sua história) (PIRES, 1997, p. 86).

O método materialista histórico-dialético (MHD), com a crise do socialismo real, sistema político, econômico e social, tem sido bastante questionado como referencial teórico de compreensão da realidade. No entanto, para Sousa Santos (1996), vale a pena observar que as interpretações marxistas sobre as dimensões econômica, social, política e cultural da sociedade capitalista moderna, continuam como interpretações consistentes e originais, sobrevivendo ao estágio capitalista atual, com isso, conferindo atualidade e pertinência ao método, mesmo que precise ser constantemente contextualizado (SOUSA SANTOS, 1996).

Ainda se referindo ao método MHD, Alves (2010, p. 4) afirma:

O método de Marx, embora naturalista e empírico, não é positivista, mas sim realista. Sua dialética epistemológica leva-o também a uma dialética ontológica específica (um conjunto de leis ou princípios que governam um setor ou a totalidade da realidade) e a uma dialética relacional condicional (o movimento da história).

Pires (1997) defende que é necessário compreender o método MHD para nos instrumentalizarmos no processo de compreensão da realidade. Justifica sua defesa, afirmando que tal método caracteriza-se "[...] pelo movimento do pensamento através da materialidade histórica da vida dos homens em sociedade, isto é, trata-se de descobrir (pelo movimento do pensamento) as leis fundamentais que definem a forma organizativa dos homens durante a história da humanidade" (p. 87). 
O princípio da contradição, presente nesta lógica, indica que para pensar a realidade é possível aceitar a contradição, caminhar por ela e apreender o que dela é essencial. Neste caminho lógico, movimentar o pensamento significa refletir sobre a realidade partindo do empírico (a realidade dada, o real aparente, o objeto assim como ele se apresenta à primeira vista) e, por meio de abstrações (elaborações do pensamento, reflexões, teoria), chegar ao concreto: compreensão mais elaborada do que há de essencial no objeto, objeto síntese de múltiplas determinações, concreto pensado. Assim, a diferença entre o empírico (real aparente) e o concreto (real pensado) são as abstrações (reflexões) do pensamento que tornam mais completa a realidade observada (PIRES, 1997, p. 87).

O pensamento materialista histórico-dialético pode ser entendido como um caminho epistemológico que fundamenta o conhecimento para a interpretação da realidade histórica e social, no esforço para se captar, detalhadamente, as articulações dos problemas, analisar as evoluções e rastrear as conexões sobre os fenômenos que os envolvem. Portanto, das alusões ao método materialista histórico-dialético é possível se depreender importantes contribuições para orientar estudos territoriais. Destaca-se, em especial, a importância do princípio da contradição, da totalidade e da historicidade no processo de compreensão e análise de realidades complexas, como é o caso de contextos socioeconômicos, históricos e culturais, em recortes espaciais representados por municípios, regiões ou territórios.

\section{A perspectiva epistemológica sustentada no descentramento e decolonialidade e sua relação com o enfoque territorial}

A revisão das epistemologias modernas impõe-se como desafio teórico para a inteligibilidade do mundo em sua hibridez, bem como o desafio ético e político, na medida em que explicita a exclusão e o silenciamento de sujeitos levados à desumanização, tendo seus saberes e cosmovisões negados como explicativos e orientadores legítimos de condutas (MIGLIEVICH-RIBEIRO, 2014). Ao dialogar com a perspectiva da necessidade de revisão das epistemologias, a discussão sobre decolonialidade, como um movimento teórico, ético e político questiona as pretensões de objetividade do conhecimento dito científico dos últimos séculos, em especial, no campo das ciências sociais.

O que se convencionou chamar de decolonialidade ou pós-colonialismo, na forma de conjunto de contribuições teóricas oriundas principalmente dos estudos literários e culturais ${ }^{14}$, também entendido como método de "desconstrução dos essencialismos", trata, portanto, da proposta de "[...] uma epistemologia crítica às concepções dominantes de modernidade" (COSTA, 2006, p. 83-84).

Sousa Santos (2009) postula o exercício do descentramento como pressuposto para captar a totalidade do que está ocorrendo no mundo contemporâneo. Neste sentido, o autor desenvolveu o que denomina de "Epistemologias do Sul". Trata-se, pois, de propor, a partir da diversidade do mundo, um pluralismo epistemológico que reconheça a existência de múltiplas visões que contribuam para o alargamento dos horizontes da mundaneidade, de experiências e práticas sociais e políticas alternativas. Portanto, para o autor, a expressão Epistemologias do Sul é uma metáfora do sofrimento, da exclusão e do silenciamento de povos e culturas que, ao longo da História, foram dominados pelo capitalismo e colonialismo. O colonialismo constitui o grau zero a partir do qual são construídas as concepções contemporâneas de modernidade, sendo estas, importantes, tanto por aquilo que dizem, quanto por aquilo que silenciam (SOUZA SANTOS, 2009).

A colonialidade é um dos elementos constitutivos e específicos do padrão mundial de poder capitalista. Se funda na imposição de uma classificação racial/étnica da população do mundo como pedra angular do dito padrão de poder e opera em cada um dos planos, âmbitos e dimensões materiais e subjetivas, da existência social cotidiana e da escala social. Origina-se e mundializa-se a partir da América (QUIJANO, 2000, p. 342).

Na mesma linha de pensamento, para Dussel (2000), a modernidade é um mito que oculta a colonialidade, pois: (i) a civilização moderna, de caráter eurocêntrico, autodescreve-se como desenvolvida e superior; (ii) a superioridade indica que os mais pobres, primitivos, ou bárbaros é quem precisa serem "desenvolvidos" e que o caminho a ser galgado é o que foi feito pelos países

\footnotetext{
14 Outra compreensão referida ao termo é como tempo histórico posterior aos processos de descolonização do chamado "terceiro mundo", referindo-se à independência, libertação e emancipação das sociedades exploradas pelo imperialismo e neocolonialismo, especialmente nos continentes asiático e africano. Esta compreensão não será aqui explorada, como destacado por Mignolo (2010).
} 
europeus; (iv) como o "bárbaro" se opõe a esse tipo de processo civilizador, se necessário, justificase a violência para destruir os obstáculos dessa modernização. $O$ autor também se refere ao padrão de desenvolvimento eurocêntrico, como unilinear e à europeia, o que determina, mesmo que de modo inconsciente, a "falácia desenvolvimentista".

No entanto, o processo de decolonialização não deve ser confundido com a rejeição da criação humana realizada pelo Norte global e associado com aquilo que seria genuinamente criado no Sul. Precisa ser entendido, muito mais, como contribuições de autores e autoras, situados tanto nos centros quanto nas periferias da produção da geopolítica do conhecimento, que questionam o universalismo etnocêntrico, o eurocentrismo teórico, o nacionalismo metodológico, o positivismo epistemológico e o neoliberalismo científico, contidos no mainstream das ciências sociais. Assim, decolonializar a teoria, em especial a teoria política, é um dos passos para decolonialização do próprio poder (BALLESTRIN, 2013).

Na Geografia, Milton Santos, ainda nos anos 1970 e 1980, levantava questóes convergentes com o que se conhece hoje como perspectivas epistemológicas sustentadas no descentramento e decolonialidade. Dantas (2014), ao fazer aproximações entre as "epistemologias do Sul", de Boaventura de Sousa Santos, e a obra de Milton Santos, destaca que esta última tem como uma de suas principais preocupações a proposição de uma epistemologia geográfica adequada para a análise do "Sul".

Santos (2014), no livro cuja versão original é de 1987, denominado $O$ espaço do cidadão, sugere o que chamou de "modelo cívico-territorial", para se referir à reconversão da cidadania abstrata em cidadania concreta, mediante um planejamento, uma gestão e um ordenamento do território voltados à redistribuição equitativa dos recursos sociais e à atribuição de bens e serviços a todos os seus habitantes. Essa proposição, sustenta-se na crítica que o autor faz ao fato de que, quando são pensados planos ou estratégias de desenvolvimento para regiões ou territórios, se tomam os setores mais dinâmicos da economia como referência, esquecendo que os circuitos de fabricação, distribuição e consumo são bastante diferenciados, em especial, se considerarmos as áreas urbanas periféricas.

Foi para melhor caracterizar essa questão, que em outra publicação, Santos (2008) propôs que na economia urbana dos países pobres fossem considerados dois setores: (i) o circuito superior, diretamente associado aos setores corporativos de reprodução econômica, modernos tecnologicamente; (ii) o circuito inferior, associado às formas de reprodução social das populações mais pobres, usualmente dependentes do trabalho mais do que do capital.

Assim, Santos (2008) considerou que o uso da expressão "setor informal" para se referir às atividades socioeconômicas do que chamou de circuito inferior, era irracional, no sentido weberiano do termo, em que a organização dita "formal" seria a racional, uma perspectiva etnocêntrica, que não considera as condições de trabalho, de consumo, de crédito e de infraestrutura das economias pobres dos países subdesenvolvidos. Alternativamente a essa compreensão etnocêntrica, Milton Santos propôs entender o conjunto de atividades de fabricação artesanal, de pequenos comércios e serviços e de transporte não modernos, como um sistema econômico dotado de características muito particulares e cujos dinamismos e mecanismos de funcionamento, frequentemente, escapam do alcance das políticas de desenvolvimento (LEITE; TRINDADE JÚNIOR, 2020).

Pode-se observar, portanto, que as contribuições contemporâneas sobre decolonialidade ou pós-colonialismo, aportam questões mais relacionadas às questões de ordem sócio-político-cultural, enquanto a contribuição da Geografia complementa esse debate, com questões socioeconômicas, focadas no planejamento e gestão territorial. Ou seja, ambas as contribuições são complementares e indispensáveis para fundamentar estudos regionais ou territoriais, como os que se propõem orientarse pela perspectiva territorial.

Estas breves reflexões, em síntese, sugerem que pensar o desenvolvimento (local, regional, territorial), tendo o patrimônio territorial como referência, implica em que, as prospecções que sejam feitas, contemplem, equitativamente, os "bárbaros" da contemporaneidade, ou seja, os segmentos ainda excluídos das benesses que podem ser oportunizadas pela evolução tecnológica atual. Implica também considerar no planejamento o circuito inferior da economia urbana e regional, enfim, convergir para o que Milton Santos chama de "modelo cívico-territorial", tudo isso, sustentado em um referencial epistemológico de caráter descentrador e decolonial. Trata-se, em tese, da tentativa de priorizar concepções epistemológicas que evitem a exclusão e o silenciamento de sujeitos, com seus saberes e cosmovisões, muitas vezes, negados como explicativas e orientadoras legítimos de condutas, seja de minorias ou grupos marginalizados e/ou despossuídos. 
Por fim, a expressão "bárbaros", a qual tem uma origem histórica para se referir aos povos ou indivíduos que não se submetiam aos preceitos civilizatórios ocidentais, contemporaneamente, pode ser referida aos que estão excluídos da sociedade moderna, por motivos ético-culturais, socioeconômicos, comportamentais ou por não se adequarem às exigências da modernidade tecnológica. Isso tudo implica em que, pensar o desenvolvimento na perspectiva territorial, representa, também, uma tentativa de superar a dita falácia desenvolvimentista, pelo atendimento dos desejos e interesses plurais que existem nos territórios.

\section{Pressupostos teóricos a serem considerados na análise territorial: uma indicação propositiva}

Numa visão platônica, conforme transcrito em sua obra República, a episteme é concebida como conhecimento da realidade das coisas, um saber pleno de certeza, enquanto seu contrário, a doxa, é reafirmada como simples opinião, sujeita ao seu falseamento. Um pressuposto é compreendido como aquilo que se pode supor de forma antecipada com base em hipóteses, indícios ou convicções. Assim entendido, um pressuposto epistêmico refere-se a um conjunto organizado de conhecimentos que antecipa e orienta nossa interpretação e/ou compreensão de uma determinada realidade. Uma determinada concepção teórica se fundamenta em um pressuposto epistêmico. Já as concepções teóricas orientam nossas práticas de estudo da realidade, indicando os procedimentos metodológicos mais adequados para tal.

Sobre a questão dos procedimentos metodológicos, retorna-se ao tema em outro momento. Nesta parte do texto, faz-se o apontamento de categorias teóricas centrais que dialoguem com pressupostos epistêmicos convergentes com a abordagem territorial.

A presente indicação propositiva orienta-se em reflexões teóricas precedentes, sintetizadas em três publicações (DALLABRIDA, 2020a; 2020b; 2020c). Uma primeira reflexão está presente no artigo Significar Territórios como Estratégia de Diferenciação: aportes teóricos e metodológicos, no qual é ressaltado que "significar territórios" refere-se ao ato de atribuir-lhe uma marca convencionada para distingui-los como recortes espaciais específicos, incluindo sua gente, suas tradições históricas, suas formas de sobrevivência e/ou seus produtos diferenciados, como estratégia de reafirmação das especificidades do território e sua identidade. Parte-se da premissa de que as possibilidades de ampliar a competitividade de territórios ou regiões, aumentam ou não, dependendo da capacidade de organização socioterritorial, qualidade e características específicas dos produtos que oferecem ao mercado. Como conclusão central, afirma-se no artigo que, significar territórios, implica reafirmar a valorização da dimensão territorial nos processos de desenvolvimento (DALLABRIDA, 2020a).

Uma segunda reflexão é feita no artigo Patrimônio Territorial: abordagens teóricas $e$ indicativos metodológicos para estudos territoriais, no qual são revisadas as bases teóricas que originam a abordagem sobre patrimônio territorial. No artigo, o patrimônio territorial é concebido como o conjunto de ativos e recursos, materiais e imateriais, que se acumularam ao longo da história num determinado território, resultante de processos históricos de construção e reconstrução socioeconômica e cultural, na relação com o entorno ambiental. Inclui tanto os elementos herdados do passado longínquo, quanto os que se sobrepõem ao território constantemente. Considera-se o patrimônio territorial como referência e ponto de partida nos processos de intervenção e análise territorial, em especial, quando se trata de demandas relacionadas ao planejamento e à gestão (DALLABRIDA, 2020b) ${ }^{15}$.

Por fim, uma terceira reflexão contemplada no artigo Território e Governança Territorial, Patrimônio e Desenvolvimento Territorial: estrutura, processo, forma e função na dinâmica territorial do desenvolvimento, no qual se propõe relacionar as categorias de análise geográfica, estrutura, processo, forma e função, propostas pelo geógrafo brasileiro Milton Santos, à dinâmica territorial do desenvolvimento. O texto parte da discussão teórica para elaborar uma síntese na forma de interpretação geográfica dos processos territoriais, finalizando com indicativos metodológicos que abalizam o patrimônio territorial e seus componentes, como ponto de partida e diretriz na elaboração de estratégias localizadas de desenvolvimento. O objetivo central é a proposição de um referencial para se pensar novas possibilidades na dinâmica de desenvolvimento localizado, tendo a ativação do patrimônio territorial como a estratégia central (DALLABRIDA, 2020c).

\footnotetext{
${ }^{15}$ Sobre patrimônio territorial, duas publicações referência: Magnaghi (2015); Poli (2015).
} 
A figura 1 reproduz as diferentes inter-relações entre as quatro categorias teóricas centrais - território, governança territorial, patrimônio territorial, desenvolvimento territorial -, considerando processos de territorial do desenvolvimento.

Figura 1: Uma interpretação geográfica do processo de desenvolvimento territorial

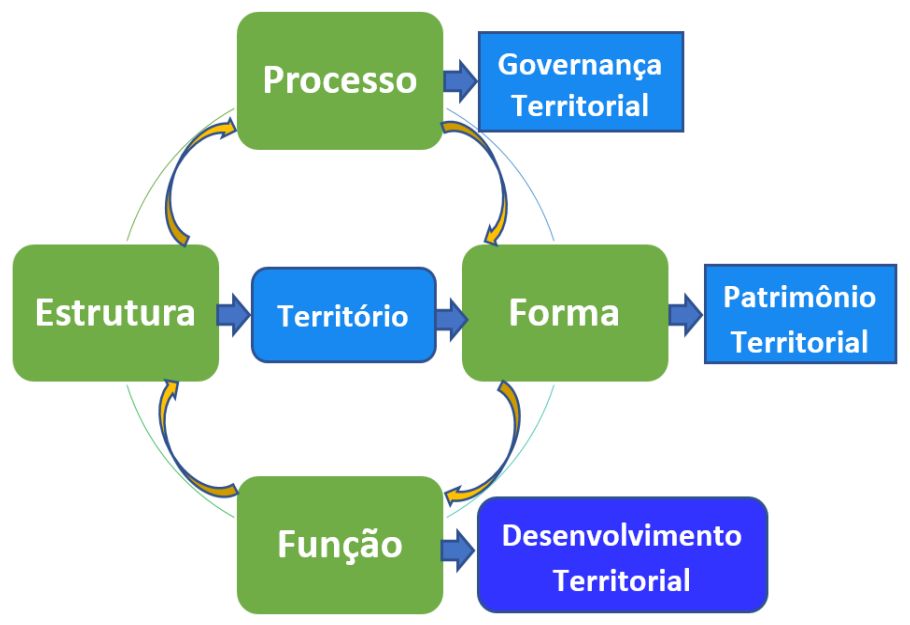

Fonte: Dallabrida (2020c, p. 71)

As quatro categorias teóricas, como explicativas dos processos de desenvolvimento territorial, assim podem ser compreendidas:

a- Categoria de partida: o território, uma estrutura socioterritorial em que suas partes se interrelacionam, constituindo o mundo natural, das organizações e da produção;

b- Categoria de intermediação: a forma assumida temporal e historicamente por uma estrutura, resulta de relações socioambientais, por meio de "conversações societárias horizontais", ou seja, práticas de governança territorial (DALLABRIDA, 2007, 2015; FARINÓS, 2015), processo em que são confrontados diferentes interesses/intenções, com o propósito de construir convergências quanto ao futuro desejado territorialmente;

c- Categoria resultante: toda estrutura, temporal e historicamente construída, assume uma forma, neste caso, representada pelo patrimônio territorial;

d- Categoria de funcionalidade: do confronto entre diferentes projetos de futuro, resultam configurações espaciais, demarcadas administrativamente (municípios, regiões, países) ou por relações de identidade, ancoragem e pertencimento a um lugar (territórios), como função da forma; tais configurações espaciais transitam entre a utopia desejada pelas pessoas envolvidas nos processos de ação coletiva que ocorrem nos municípios, regiões, países ou territórios, e a realidade possível; o que se argumenta é que, o que chamamos desenvolvimento territorial (ou local/regional) faz parte da utopia desejada e sua concretude momentânea, representando a realidade possível; como os agentes de tais processos, nem sempre dispõem de poder equivalente de persuasão ou decisão, o futuro desejado não necessariamente atende aos interesses do todo, às vezes, nem mesmo da maioria dos interlocutores, o almejado "desenvolvimento" permanece muito mais na condição de utopia de que de realidade (DALLABRIDA, 2020c).

Duas questões complementares para compreender a proposição indicativa aqui expressa. Primeira, quanto às configurações espaciais que se apresentam como função da forma, vale dar atenção à contribuição de Pecqueur (1992), ao afirmar que a noção de território apresenta a dupla dimensão: (i) de território-dado, recortes territoriais demarcados administrativamente (municípios, regiões, países); (ii) territórios-construídos, recortes territoriais demarcados por atores sociais que desfrutam de proximidade geográfica, por meio de relações de identidade, ancoragem e pertencimento a um lugar (territórios), buscando assim resolver problemas socioprodutivos compartilhados. São essas configurações espaciais que resultam da dinâmica territorial do desenvolvimento ${ }^{16}$.

${ }^{16}$ Büttenbender e Sausen (2020) fundamentam a estratégia articulatória e convergente, decisiva na combinação de três arranjos, oferecendo um constructo ilustrativo que sustenta esta abordagem. 
A segunda questão, trata-se da necessidade de não esquecermos de que o território é um todo paradoxal, permeado de contradições entre elementos interdependentes. As contradições fazem parte do contexto contemporâneo, não são anomalias a evitar ou a eliminar, mas antes uma decorrência do próprio processo organizacional. Por outras palavras, não são interrupções à ordem organizacional, mas parte dessa mesma ordem. Assim, uma decisão sobre uma matéria tem implicações para uma matéria situada num polo oposto. Esses dois polos formam uma dualidade. No entanto, se a relação entre a tensão for usada como fonte de sinergia, o paradoxo pode tornar-se uma janela aberta a novas possibilidades. Essa fonte de sinergia é possível de ser gerada e potenciada, pela ação coletiva, democrática, partilhada e horizontal entre os diferentes atores territoriais. Relações sociais de caráter identitário e de pertencimento territorial permitem que essa sinergia seja gerada, subsista e possa multiplicar-se.

Boisier (1999) refere-se a essa sinergia como sendo o capital sinergético. O autor propõe apoiar-se no conceito de capital territorial (ou patrimônio territorial) para potenciar e articular novas formas de capital, quase todas de caráter intangível, a fim de colocar o território na "senda virtuosa do desenvolvimento". Trata-se de questões cognitivas, simbólicas, culturais, sociais, cívicas etc., que parecem vincular-se estreitamente com uma contemporânea concepção de desenvolvimento, em que a construção de infraestruturas e outras ações materiais, mesmo que valiosas em si mesmo, não conduzem necessariamente ao desenvolvimento.

\section{Considerações finais}

Propôs-se neste artigo a identificação dos pressupostos epistêmico-teóricos convergentes com a abordagem territorial. Referir-se à abordagem territorial, é conceber o território como referência fundamental em processos de intervenção, planejamento ou gestão territorial.

Resumindo, o entendimento que aqui quer se ressaltar é que a abordagem territorial do desenvolvimento (i) atende a um propósito central, tal seja, ser uma alternativa de superação de análises de recortes espaciais, sejam eles rurais ou urbanos, centrados em procedimentos disciplinares e/ou setoriais, (ii) como uma condição para a realização de estudos que assumam a realidade socioeconômica, cultural e ambiental, de forma integrada, reconhecendo sua complexidade.

Reafirma-se no decorrer do artigo que a abordagem territorial considera o território como parte da totalidade espacial, em que se expressa a diversidade, a relacionalidade e interação entre atores, a interdependência entre as dimensões tanto materiais quanto imateriais e o lócus de manifestação de sistemas produtivos territoriais, de mediação e interdependência entre seres humanos e demais espécies de vida.

Sobre a base epistêmico-teórica que sustenta a abordagem territorial, destaca-se a necessidade de contemplar os princípios da totalidade, diversidade, especificidade, pluralismo, relacionalidade, integração, interdependência sistêmica, autonomia de ação e mediação entre as partes constituintes. Conclui-se no texto, por decorrência, que as principais correntes epistemológicas fundamentadas em tais princípios são a nova teoria dos sistemas, a teoria da complexidade, o materialismo histórico-dialético e a perspectiva epistemológica sustentada no descentramento e decolonialidade, por entender que tais enfoques apresentam uma estreita relação com a abordagem territorial, no sentido de terem em comum o propósito de superação de abordagens centradas em pretensões de objetividade do conhecimento dito científico, na perspectiva de desconstrução dos essencialismos eurocêntricos.

A motivação principal para se propor a elucidação dos pressupostos epistêmico-teóricos convergentes com a abordagem territorial, deve-se à iniciativa de execução de um projeto de pesquisa, envolvendo um grupo de intelectuais brasileiros, latino-americanos e europeus, cujo objetivo central é elaborar estudos, propor e validar um referencial metodológico com o fim de contribuir na execução de diagnósticos territoriais que permitam a prospecção de alternativas inovadoras e sustentáveis de desenvolvimento, tendo o patrimônio territorial como referência. Mesmo que, inicialmente, este texto tenha a pretensão de servir de suporte teórico-epistemológico, para orientar a execução desse projeto, o mesmo poderá servir de referência a outros estudos focados na perspectiva territorial.

Não se pretende aludir que os pressupostos epistêmico-teóricos aqui referidos sejam os únicos que convirjam com a abordagem territorial. No entanto, pode-se afirmar serem os mais indicados, considerando a base epistêmico-teórica referida. 
O desafio na sequência é indicar pressupostos metodológicos convergentes com o estudo da realidade territorial, que permitam dar cumprimento à análise territorial. Esses pressupostos servirão de base para a estruturação de um referencial metodológico, a ser validado na sequência, pela sua aplicação ${ }^{17}$. O referencial metodológico pretendido precisa atender a um propósito central, tal seja, ser uma alternativa de superação de técnicas e procedimentos tradicionais, centrados em abordagens disciplinares e/ou setoriais, como condição essencial para a realização de estudos que assumam integralmente a perspectiva territorial. No entanto, considerando que se deva enfrentar um desafio por vez, pretende-se chegar ao objetivo pretendido no seu tempo, num outro momento.

\section{Referências}

ABRAMOVAY, R. Para uma teoria dos estudos territoriais. In: VIEIRA, P. H. F. et al. (org.). Desenvolvimento Territorial Sustentável no Brasil: subsídios para uma política de fomento. 1. ed. Florianópolis: APED/Secco, 2010. p. 27-47.

ABRAMOVAY, R. O capital social dos territórios - repensando o desenvolvimento rural. Economia Aplicada, v. IV, n. 2, p. 379-397, 1999.

ALVES, A. M. O método materialista histórico dialético: alguns apontamentos sobre a subjetividade. Revista de Psicologia da UNESP, v. 9, n. 1, p. 1-13, 2010.

ANDRADE, É. Uma crítica à Teoria da Complexidade proposta por Edgar Morin. Dissertatio, Pelotas, v. 26, p. 167-187, 2007. Doi: https://doi.org/10.15210/dissertatio.v26i0.8895.

BACHELARD, G. A epistemologia. Lisboa: Edições 70, 1990.

BALLESTRIN, L. América Latina e o giro decolonial. Rev. Bras. Ciênc. Polít., n. 11, n. 11, p. 89-117, 2013. Doi: https://doi.org/10.1590/S0103-33522013000200004.

BAUER, R. Gestão da mudança: caos e complexidade nas organizações. São Paulo: Atlas, 2009.

BECHMANN, G.; STEHR, N. Niklas Luhmann. Tempo Social, São Paulo, v. 13(2), p. 185-200, nov. 2001.

BENKO, G.; PECQUEUR, B. Os recursos de territórios e os territórios de recursos. Geosul, Florianópolis, v. 16, n. 32, p 31-50, jul./dez. 2001.

BERDEGUÉ, J.; FAVARETO, A. S. Balance de la experiencia latino-americana de desarrollo territorial rural y propuestas para mejorarla. In: BERDEGUÉ, J.; CHRISTIAN, C.; FAVARETO, A.

S. Quince años de desarrollo territorial rural em América Latina: qué nos muestra la esperiencia? 1. ed. Ciudad Autónoma de Buenos Aires: Teseo, 2020. p. 11-57.

BOISIER, S. El desarrollo territorial a partir de la construcción de capital sinergético. R. B. Estudos Urbanos e Regionais, n. 2, p. 39-53, nov./1999.

BÜTTENBENDER, P. L.; SAUSEN, J. O. Innovative development management practices in a border region: a construct proposal of innovative governance andterritorial development. Revista Brasileira de Gestão e Desenvolvimento Regional, v.16, p. 446-458, 2020.

CAPRA, F. A teia da vida: uma nova compreensão científica dos sistemas vivos. São Paulo: Cultrix, 1996.

COSTA, S. (2006). Dois Atlânticos: teoria social, anti-racismo e cosmopolitismo. Belo Horizonte: Editora UFMG, 2006.

COULERT, C.; PECQUEUR, B. Os sistemas industriais locais em França. In: BENKO, C.; LIPIETZ, A. (org.). As regióes ganhadoras: distritos e redes os novos paradigmas da geografia econômica. Oeira: Celta Editora, 1994.

\footnotetext{
${ }^{17}$ Esse será outro desafio a ser pensado na sequência. Tais pressupostos serão apresentados em texto que está no prelo: Dallabrida et al. (2021).
} 
CUNHA, M. P.; REGO, A.; SOUSA, M. Como podem as organizações gerir paradoxos? Aná. Psicológica, Lisboa, v. 34, n. 3, p. 309-323, set. 2016. Doi: http://dx.doi.org/1014417/ap.1203.

DALlABRIDA, V. R. Significar Territórios como Estratégia de Diferenciação: Aportes Teóricos e Metodológicos. Caderno de Geografia, v.30, n.60, p. 196-213, 2020a. Doi: https://doi.org/10.5752/P.2318-2962.2020v30n60p196-213.

DALLABRIDA, V. R. Da Cidade Inteligente, ao Território Inovador, rumo à Inteligência Territorial: aproximações teóricas e prospecções sobre o tema. Revista Desenvolvimento em Questão, ano 18, n. 53, p. 46-71, 2020b. Doi: http://dx.doi.org/10.21527/2237-6453.2020.53.46-71.

DALLABRIDA, V. R. Território e Governança Territorial, Patrimônio e Desenvolvimento Territorial: estrutura, processo, forma e função na dinâmica territorial do desenvolvimento. G\&DR - Revista Brasileira de Gestão e Desenvolvimento Regional, v. 16, n. 2, p. 63-78, mai-ago/2020c.

DALLABRIDA, V. R. Patrimônio Territorial: abordagens teóricas e indicativos metodológicos para estudos territoriais. Desenvolvimento em Questão, v. 18, n. 52, p. 12-32, jul./2020d. DOI: https://doi.org/10.21527/2237-6453.2020.52.12-32.

DALlABRIDA, V. R. Teorias do Desenvolvimento: aproximações teóricas que tentam explicar as possibilidades e desafios quanto ao desenvolvimento de lugares, regióes, territórios ou países. Curitiba: Editora CRV, 2017.

DALLABRIDA, V. R. Governança territorial: do debate teórico à avaliação da sua prática. Análise Social, v. $\quad \mathrm{L}\left(2^{\circ}\right), \quad$ n. $215, \quad$ p. 304-328, 2015. Disponível em: http://www.scielo.mec.pt/pdf/aso/n215/n215a04.pdf. Acesso em: 27-01-2021.

DALLABRIDA, V. R. A gestão territorial através do diálogo e da participação. Scripta Nova, Barcelona, v. XI, n. 245 (20), 1 de agosto de 2007. Disponível em: http://www.ub.es/geocrit/sn/sn24520.htm. Acesso em: 27-01-2021.

DALLABRIDA, V. R.; ROTTA, E.; BÜTTENBENDER, P. L.; ARENHART, L. O.; DENARDIN, V. F. Abordagem territorial do desenvolvimento: categorias conceituais e pressupostos metodológicos. Guaju - Revista Brasileira de Desenvolvimento Territorial Sustentável, v. 7, n. 1, 2021.

DANTAS, A. Geografia e epistemologia do sul na obra de Milton Santos. Mercator, Fortaleza, v. 13, n. 3, p. 49-61, set./dez. 2014.

DUSSEL, E. Europa, modernidad y eurocentrismo. In: LANDER, E. (Coord.). La colonialidad del saber: eurocentrismo y ciencias sociales, perspectivas latinoamericanas. Buenos Aires: Clacso, 2000.

FARINÓS, J. Desarrollo Territorial y Gobernanza: refinando significados desde el debate teórico pensando en la práctica. Un intento de aproximación fronética. Desenvolvimento Regional em debate, v. 5, n. 2, p. 4-24, jul./dez. 2015.

FAVARETO, A. S. A abordagem territorial do desenvolvimento rural: mudança institucional ou inovação por adição? Estudos Avançados (USP. Impresso), v. 24, p. 299-319, 2010.

FAVARETO, A. Multiescalaridade e multidimensionalidade nas políticas e nos processos de desenvolvimento territorial: acelerar a transição de paradigmas. SILVEIRA, R. L. L.; DEPONTI, C. M. (org.). Desenvolvimento regional: processos, políticas e transformações territoriais. São Carlos: Pedro \& João Editores, 2020. p. 61-91.

FAVARETO, A. Paradigmas do desenvolvimento rural em questão. São Paulo: Ed. Iglu/Fapesp, 2007.

FUINI, L. L. Construções teóricas sobre o território e sua transição: A contribuição da Geografia brasileira. Cuadernos de Geografía - Revista Colombiana de Geografía, Bogotá, Colombia (en línea), v. 26, n 1, p. 221-242, ene.-jun. del 2017. Doi: dx.doi.org/10.15446/rcdg.v26n1.56791.

GUSDORF, G. La parole. Paris: Presses Universitaires de France, 1953.

JAPIASSU, H. Interdisciplinaridade e patologia do saber. São Paulo: Imago, 1976. 
JAPIASSU, H. Questões epistemológicas. Rio de Janeiro: Imago, 1981.

LAGO, I. C.; ROTTA, E. Sobre a relação entre cultura e desenvolvimento: alguns apontamentos em defesa do conceito antropológico de cultura. REDES, Santa Cruz do Sul, v. 23, n. 3, p. 353-366, set./dez. 2018.

LEITE, G. C. S.; TRINDADE JÚNIOR, S.-C. C. “Geografias do Sul”: descentramento, transescalaridade e espacializações no pensamento miltoniano. Geosul, Florianópolis, v. 35, n. 76, p. 39-65, set./dez. 2020. Doi: http://doi.org/10.5007/2177-5230.2020v35n76p39.

LIMA, P. G. Ciência e Epistemologia: reflexões necessárias à pesquisa educacional. Quaestio, Sorocaba (SP), v. 12, p. 109-138, nov. 2010.

LONG, Norman. Sociologia del desarrollo: uma perspectiva centrada em el actor. México: Centro de Investigaciones y Estudios Superiores en Antropología Social, 2007.

LUCAS JR, H. C. Sistemas de Información. Madrid: Editorial Paraninfo, 1987.

LUHMANN, N. Die Gesellschaft der Gesellschaft. Frankfurt: Suhrkamp, 1997. 2 vols.

MAGNAGHI, A. Mettere in comune il patrimonio territoriale: dalla partecipazione all'autogoverno". Glocale, Rivista molisana di storia e scienze sociali, n. 9/10, p. 139-157, 2015.

MIGLIEVICH-RIBEIRO, A. Por uma razão decolonial. Desafios ético-político-epistemológicos à cosmovisão moderna. Civitas, Porto Alegre, v. 14, n. 1, p. 66-80, jan.-abr. 2014.

MIGNOLO, W. Desobediencia epistémica: retórica de la modernidad, lógica de la colonialidad y gramática de la descolonialidad. Argentina: Ediciones del signo, 2010.

MOELLER, H. G. O paradoxo da teoria. Interpretando Niklas Luhmann. Tradução do inglês de Patrícia da Silva Santos, Tempo soc., São Paulo, v .27, n.2, p. 168-179, July/Dec./2015. Doi: http://dx.doi.org/10.1590/0103-2070201528.

MORIN, E. Introdução ao pensamento complexo. 3. ed. Porto Alegre: Sulina, 2007.

MORIN, E. Ciência com consciência. 8. ed. Rio de Janeiro: Bertrand Brasil, 2005a.

MORIN, E. 0 método 5: a humanidade da humanidade. 3. ed. Porto Alegre: Sulina, 2005b.

MORIN, E. O problema epistemológico da complexidade. 2. ed. Lisboa: Europa-América, 1996.

NOVELLI, P. G. A.; PIRES, M. F. C. A dialética na sala de aula. Botucatu: UNESP, 1996.

PECQUEUR, B. Territoire, territorialité et développement: industrie et territorie - les SPL. Colloque IREPD, Grenoble, outubro, 1992.

OLIVIER DE SARDAN, J.-P. De la nouvelle anthropologie du développement à la socioanthropologie des espaces publics africains. REVUE TIERS MONDE, n. 191, p. 543-552, jul./set. 2007. Disponível em: https://www.cairn.info/revue-tiers-monde-2007-3-page-543.htm . Acesso em: 13 mar. 2021.

PIORE, K. J.; SABEL, C. F. The second industrial divide: possibilities for propserity. New York: Basic Books, 1984.

PIRES, M. F. C. O materialismo histórico-dialético e a Educação. Interface - Comunic., Saúde e Educ., Botucatu, v.1, n. 1, p. 83-94, Aug./1997.

POLI, D. Il patrimonio territoriale fra capitale e risorsa nei processi di patrimonializzazione proativa. In: MELONI, B. (a cura di). Aree interne e progetti d'area. Torino: Rosenberg e Sellier, 2015. p. 123-140.

QUIJANO, A. Colonialidad del poder y clasificación social. Journal of world-systems research, v. 11, n. 2, p. 342-386, 2000.

RAFFESTIN, C. Por uma Geografia do Poder. São Paulo: Ática, 1993. 
RAMBO, A. G.; FILIPPI, E. E. A abordagem territorial e escalar nos estudos sobre o desenvolvimento rural: uma proposta teórico-metodológica. Ambiência, Guarapuava (PR), v. 8 Ed. Especial, p. 699-719, nov. 2012.

RAUD, C. Indústria, território e meio ambiente no Brasil: perspectivas da industrialização descentralizadas a partir da análise da experiência catarinense. Florianópolis/Blumenau: Ed. UFSC/Ed. FURB, 1999.

SANTOS, L. M. L.; PELOSI, E. M.; OLIVEIRA, B. C. S. C. M. Teoria da Complexidade e as múltiplas abordagens para compreender a realidade social. Serv. Soc. Rev., Londrina, v. 14, n. 2, p. 47-72, Jan./Jun. 2012. DOI: 10.5433/1679-4842.2012v14n2p47.

SANTOS, M. O espaço do cidadão. 7. ed. São Paulo: EDUSP, [1987] 2014.

SANTOS, M. O espaço dividido: os dois circuitos da economia urbana dos países subdesenvolvidos. 2. ed. São Paulo: EDUSP, [1979] 2008.

SAQUET, M. Abordagens e concepções de território. São Paulo: Expressão Popular, 2007.

SCHAD, J.; LEWIS, M.; RAISCH, S.; SMITH, W. K. Paradox research in management science: The first 25 years and the next 25 years. Trabalho apresentado no Colóquio Anual do EGOS, Anais..., Atenas, 2-4 de julho, 2015.

SCHNEIDER, S. Ciências sociais, ruralidade e territórios: em busca de novas referências para pensar o desenvolvimento. Campo e Território, Uberlândia, v. 4, n. 7, p.24-62, 2009.

SCHNEIDER, S. A abordagem territorial do desenvolvimento rural e suas articulações externas. Sociologias, Porto Alegre, ano 6, n. 11, p. 88-12, 2004.

SCHNEIDER, S.; TARTARUGA, I. P. Território e abordagem territorial. Raízes: Revista e Ciências Sociais e Econômicas, $\quad$ v. 23, n. 1 e $2, \quad$ p. 99-116, 2004 . Doi: https://doi.org/10.37370/raizes.2004.v23.237.

SOUSA SANTOS, B. Para além do pensamento abissal: das linhas globais a uma ecologia de saberes. In: SOUSA SANTOS, B.; MENESES, M. P. (org.). Epistemologias do Sul. Coimbra: Almedina, 2009. p. 21-71.

SOUSA SANTOS, B. Renovar a teoria crítica a reinventar a emancipação social. São Paulo: Boitempo, 2007.

SOUSA SANTOS, B. Pela mão de Alice: o social e o político na pós-modernidade. São Paulo: Cortez, 1996.

THRIFT, N. The place of complexity. Theory, Culture \& Society, v.16, n.3, p.31-69, 1999.

VEIGA, J. E. Do crescimento agrícola ao desenvolvimento rural. In: CASTRO, A. C. (org.) Desenvolvimento em Debate. Rio de Janeiro: Mauad/BNDES, 2002. p. 383-409. V. II.

WANDERLEY, M. N. B. A valorização da agricultura familiar e a reivindicação da ruralidade no Brasil. Desenvolvimento e Meio Ambiente, Curitiba, n. 2, p. 29·37, jul./dez. 2000. 